\title{
Las Especies Madereras del Departamento de Tacna. Su Impacto Ecológico
}

\section{The Timber Species of the Department of Tacna. Their Ecological Impact}

\author{
${ }^{1}$ Rosario Zegarra Zegarra
}

\begin{abstract}
RESUMEN:
Se describen 16 especies perennes, silvestres, algunas de ellas cultivadas por su potencial económico, correspondientes a 08 familias y 13 géneros. Se muestra el origen de ellas, algunas son nativas de América, otras exóticas. El presente trabajo es un aporte al conocimiento de especies, las cuales proporcionan productos beneficiosos para el hombre tales como madera, taninos, colorantes, protección de suelos.
\end{abstract}

Palabras clave: perenne, nativas, exóticas, taninos, colorantes.

\section{ABSTRACT:}

16 species are described perennial, wild, some of them cultivated for their economic potential, corresponding to 08 families and 13 genera. The origin of each of them is showed, some are native from America, others exotic. This work is a contribution to the knowledge of species, which provide beneficial products for men such as wood, tannins, dyes, soil protection.

Keywords: perennial, native, exotic, tannins, dyes.

\footnotetext{
Doctor en Ciencias Biológicas, Profesora de Educación Secundaria Especialidad en Ciencias Biológicas, Bióloga

Facultad de Ciencias Agropecuarias. Universidad Nacional Jorge Basadre Grohmann
} 


\section{INTRODUCCIÓN}

Todo tipo de vegetación cumple una función importante en el medio ambiente, como el de servir de refugio a la fauna, regular recursos hidricos y el clima a nivel local.

Actualmente, en nuestro país la vegetación natural es afectada por graves problemas de un continuo deterioro a causa de la falta de fomento a la reforestación con especies nativas, tala exhaustiva de especies comerciales importantes, tala de bosques confines agropecuarios, quema de vegetación natural, insuficiencia de áreas verdes y la falta de educación en la población. Brack (2000)

Las especies exóticas se han adaptado o aclimatado a las condiciones ambientales del lugar donde fueron introducidas, es decir la facultad de adaptarse a un ambiente climático diferente del propio. En cambio las especies nativas tienen una adaptación milenaria al medio, por consiguiente menos número de plagas y enfermedades. Además son versátiles en productos y beneficios. Bueno ( 1985 .

En el presente trabajo se plantea como objetivo general la contribución al conocimiento de las especies madereras de las Provincias de Tacna, Jorge Basadre y Tarata.

Se identificaron especies de Pinophytas y Magnoliophytas, se señala el origen y la descripción botánica de cada una de ellas, así como la importancia económica, social y ecológica de las especies.

\section{MATERIALES Y MÉTODOS}

Para el presente estudio sean utilizados materiales de campo y de laboratorio, la metodología a seguir fue:

\section{a. Trabajo de campo:}

Las colecciones se realizaron en localidades de las Provincias de Tacna, Jorge Basadre y Tarata.

\section{b. Trabajo de laboratorio:}

De cada especie se tomaron ramas con hojas, flores y frutos. Los ejemplares se procesaron la conformidad con las técnicas ya conocidas. Se tomaron vistas fotográficas.

La identificación taxonómica de las especies se realizó en base a literatura especializada en flora, mediante la ayuda de claves, estudios taxonómicos.

\section{RESULTADOS}

Se describen 16 especies, de las cuales 11 son de origen americano y 5 exóticas. De éstas últimas Eucalyptus globulus "Eucalipto" es la más utilizada con fines de reforestación, y de las americanas Pimus rodiata "Pino".

Una de las especies pertenece a la División Pinophyta y las demás a la División Magnoliophyta.
Para cada especie se señalan su nombre común, origen, descripción botánica, y usos.

\section{Descripción de las especies}

\section{Pinus radiata D.Don "Pino"}

Árbol de copa amplia y redondeada. Hojas de color verde vino, aquilladas, con dos canales resiníferos, miden $10-15 \mathrm{~cm}$. de largo, reunidas en fascículos de a $3 \mathrm{o}$ de a 2 en pequeñas ramitas denominadas braquiblastos.

Flores diclino-monoicas; las masculinas amentiformes, compuestas de numerosas hojas polínicas.

Los estróbilos femeninos, axilares, laterales, formados por muchas escamas biovuladas, sustentadas por una pequeña bráctea.

Conos de 7-17 cm. de largo, son sésiles, verticilados, asimétricos, ovoides, castaños.

Semillas de color negro.

Origen: California

Importancia Económica: Ornamental y forestal de primera calidad. La madera de pino insigne se emplea en la industria de la construcción, muebles. En la industria de la celulosa se utiliza para la fabricación de cartones, cartulina, papel.

\section{Alnus acuminata Kunt "Aliso o Lambrán"}

Árbol, de hasta $20 \mathrm{~m}$. de altura. Copa irregular, angosta y abierta. Follaje perenne cuando crece en quebradas húmedas y caducifolio, en laderas semisecas.

Hojas simples, alternas ovoides o elipticas, redondeadas $o$ anchamente cuneadas en la base, agudas o brevemente acuminadas en el ápice, borde aserrado, de $4-15 \mathrm{~cm}$. de largo. Las hojas juveniles tiene una sustancia resinosa en el haz.

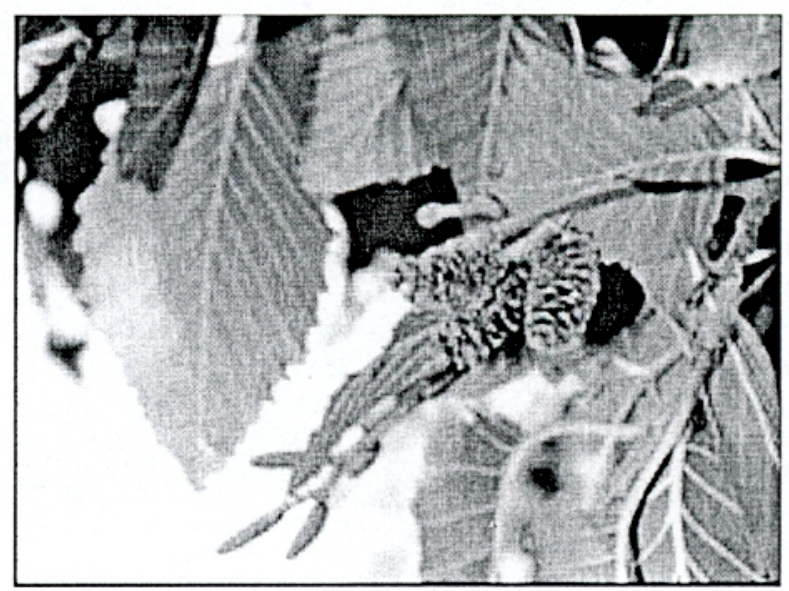

Figura $\mathrm{N}^{\circ}$ 1: Almus acuminala "Aliso o Lambran" Frutos: Falsos conos dehiscentes.

Inflorescencia: La especie es monoica. Los amentos masculinos de $7-15 \mathrm{~cm}$. de largo, son péndulos, se encuentran en la parte terminal de las ramas. De color 
verde amarillento.

Las flores femeninas con brácteas formando un cono estrobiliforme de $2-3 \mathrm{~cm}$. De largo, elipsoideos, de color verde.

Semillas elipticas, planas, bialadas, muy pequeñas.

Origen: América del Sur.

Importancia Económica: Tiene mucha utilidad, la madera se emplea para construcciones livianas, cajas, utensilios domésticos, puertas, tacos, para tallado.

La leña es de buena calidad. La corteza es rica en taninos para curtir cueros. De igual manera se usa para teñir de color amarillo-marrón la lana y el algodón, y las hojas se utilizan para teñir de amarillo y verde.

Esta especie es muy recomendable en reforestación para mejorar las condiciones de los suelos (las raices se asocian a micorrizas), pasturas naturales y estabilizadoras de torrente con problemas de erosión

\section{Casuarina equisetifolia L. "Casuarina"}

Es una especie de gran porte, que crece tanto en costas arenosas xéricas, salitrosas, como también se adapta a otras regiones. La corteza contiene gran cantidad de taninos.

La copa es piramidal, con ramitas finamente estriadas. verdes, de más o menos $0.5 \mathrm{~mm}$. de diámetro, llevando 6-8 hojuelas escasas en las articulaciones.

Las flores son unisexuales, poco vistosas y de reducido tamaño. La especie es dioica.

Las flores masculinas agrupadas en amentos rojizos, aglomerados, en la extremidad de las ramitas.

Conos elipsoideos, de color castaño, brevemente pedunculados, de más o menos $8 \mathrm{~mm}$. de largo.

Estróbilo maduro lignificado, conteniendo pequeñas sámaras de $5-8 \mathrm{~mm}$. de diámetro.

Se multiplica por semillas.

Origen: Australia,Polinesia.

Importancia Económica: Muy útil para reforestación rural y urbana en regiones templadas, trópicos y subtrópicos. Su madera es usada para placas, vallas, para leña, carbón.

Se emplea bastante como cortina rompevientos.

\section{Populus nigra L. "Alamo italiano"}

Árbol de porte columnar caducifolio, que pude alcanzar hasta $30 \mathrm{~m}$. de altura. Tronco recto, corteza gris, se resquebraja en sentido longitudinal Ramificación monopódica. Ramas laterales cortas ascendentes, pegadas al tronco.

Hojas simple, alternas, membranáceas, deltoideas, de 5 10 c. de largo, de color verde por ambas caras. acuminadas, crenado-dentadas, glabras, peciolos rojizos, delgados, comprimidos lateralmente.

Especie dioica. Las flores son unisexuales, reunidas en amentos, los masculinos cilíndricos, péndulos gruesos. rojizos, de $4-5 \mathrm{~cm}$. de largo. Amentos femeninos, mucho más largos.

Fruto: Cápsulas pequeñas con semillas algodonosas.

Origen: Nativo del Viejo Mundo.

Importancia Económica: Se utiliza como especie ornamental, en parques y jardines.

La madera es blanca y porosa, ligera, frágil, apta para carpinteria ligera de poca resistencia. Utilizada para embalajes, juguetes, palos de fösforos, marcos para cuadros y obtención de pasta de papel.

Árbol que vive en zona de ribera, con suelos fërtiles y alto grado de humedad.

\section{Salix humboldtiana Willd. "Sauce criollo"}

Árbol de gran porte, puede alcanzar hasta $10 \mathrm{~m}$. de altura. Tronco grueso y frondoso, con la corteza muy rugosa. Ramificación monopódica y copa piranidal.

Hojas simples, alternas, lanceoladas, de $5-10 \mathrm{~cm}$. de largo, acuminadas, glabras, margen crenado dentado.

Especie dioica. Las inflorescencias masculinas en amentos de $5-7 \mathrm{~cm}$. de largo. Las flores aperiantadas. protegidas por brácteas o escamas. Estambres generalmente 5. Las flores femeninas presentan el estigma bifido, ovario súpero, unilocular, con numerosos óvulos.

Fruto capsular de $5 \mathrm{~mm}$. de largo, bivalvo, con numerosas semillas algodonosas.

Origen: América del Sur.

Importancia Económica: De gran importancia, se le emplea para confeccionar canastas y muebles. Se le utiliza como una especie ornamental.

En agroforestería sirve para protección de la erosión las orillas de los ríos y canales de riego.

En medicina casera se le usa como antifebrifugo, por el contenido de salicina que presenta.

\section{Kageneckia lanceolata Ruiz \& Pav. "Lloque"}

Es un árbol pequeño de 3-4 m. de altura, y 2-3 dm. de diámetro. Su hojas son simples alternas, lanceoladas, con ápice obtuso, ligeramente mucronado, margen aserrado, penninervias, con el haz de un verde más 
intenso con referencia al envés.

Las flores son pequeñas de color blanco. Actinomorfas. Pequeñas, de color blanco. Cáliz con 5 sépalos. Corola con 5 pétalos. Estambres numerosos. El gineceo consta de 5 carpelos insertos en un tálamo plano o embudado.

Fruto en folículo.

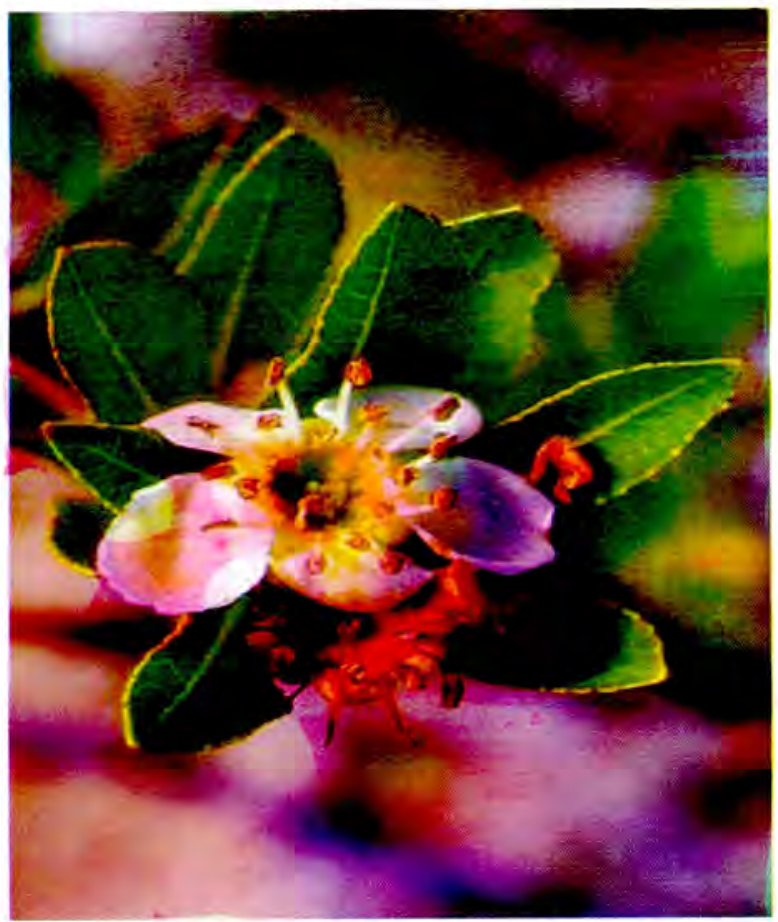

Figura $\mathrm{N}^{\circ}$ 2: Kageneckia lanceolata "Lloque"

\section{Origen: América del Sur (Perú-Bolivia)}

Importancia Económica: La madera se emplea para fabricar bastones, muy apreciados por su resistencia, para mangos de herramientas. Su leña y carbón tiene alto poder calorífico.

Las hojas sirven en tintorería para teñir de negro.

Pude ser utilizada como cerco vivo forrajero. Es una especie que tolera la aridez. Apta para retención de suelos.

Con alto potencial melífero y por sus taninos se le usa en la industria del curtido.

\section{Acacia horrida Hort "Espino"}

Es un árbol o arbusto, que en su lugar de origen mide 4-8 m. de altura, de copa ancha, tranco corto, rugoso y fisurado. Es una especie caducifolia, con espinas estipulares de $9,5 \mathrm{~cm}$. de longitud de color blanco.

Hojas bipinnadas con 2-4 pares de pinnas, cada una de las cuales presenta 5-9 pares de folíolos, pequeños, oblongos, glabros, uninervios de $5-9 \mathrm{~mm}$. de longitud.

Inflorescencia en cabezuelas amarillas, distribuidas en grupos de 4-6 en axilas de las hojas superiores. Las cabezuelas amarillo anaranjadas son hasta el $1.5 \mathrm{~cm}$. de diámetro, los pedúnculos que las sostienen miden de 1-3 cms. de longitud.

Fruto en legumbre dehiscente linear-falcada, seca bivalva, constreñida entre las semillas, mide 7-14 cms. de longitud.

Semillas longitudinales.

Origen: África del Sur.

Importancia Económica: Es una planta rústica poco exigente en suelos, resistente a la sequía. Empleada para cerco vivo, debido a sus enormes espinas.

Su madera es utilizada como combustible. Las hojas y ramas como forraje. Por la belleza de sus flores puede ser utilizada como especie ornamental.

\section{Acacia macracantha Humb \& Bonpl. "Huarango - Yaro"}

El huarango es un árbol de 5-6 m. de altura, ramificado con una copa aparasolada, en su mayor parte espinoso o con espinas algo esparcidas, pero con los extremos muy agudos. Ramas frecuentemente blanquecinas tomentosas, muy rara vez glabras.

Hojas compuestas bipinnadas, pinas de 10-60 pares aproximadamente con 20-30 pares de foliolillos que escasamente llegan a medir hasta $3 \mathrm{~mm}$. de largo, con estípulas transformadas en espinas reducidas de 1-3 cms. de longitud.

Inflorescencia en cabezuelas de color amarillento. Cáliz campanulado 5-dentado, corola amarilla gamopétala. Estambres numerosos, largamente exsertos. Gineceo con un ovario súpero cilíndrico.

Fruto. Vaina o legumbre pulverulenta recta ligeramente curvada de $5-7 \mathrm{~cm}$. de longitud.

Semillas elípticas, marrón-castañas.

Origen: América del Sur.

Importancia Económica: La madera se utiliza en construcción, por su calidad y alto poder energético es muy apreciada para leña y carbón.

Las hojas y vainas son palatables para el ganado. Por su buen desarrollo radicular es muy adecuada para consolidar y fijar suelos ribereños.

\section{Prosopis chilensis (Molina) Stuntz "Algarrobo"}

Es un árbol de altura menor que Prosopis pallida, mide entre 3-10 m. de altura. El tronco es corto, ramas largas decumbentes. La corteza de color pardo rojizo. Ramas arqueadas, flexuosas con pare de espinas de hasta $5 \mathrm{~cm}$. de largo.

Hojas compuestas, bipinnadas, pecíolo de $2-14 \mathrm{~cm}$. de longitud, con 1-3 pares de pinnas en el pecíolo. Cada 
pinna presenta 10-25 pares de foliolillos lineares.

Inflorescencia: Racimos espiciformes, cilíndricos verde blanquecinos o amarillentos de 6-12 $\mathrm{cm}$. de largo en grupos de 2-4.

Las flores son pequeñas. Cáliz acampanado. Corola con 5 pétalos libres. Estambres exertos. Ovario súpero unicarpelar.

Fruto. Lomento coriáceo o subleñoso, amarillo claro, arqueado, con manchas vinosas. Mide $9-18 \mathrm{~cm}$.

Semillas Dvaladas o elípticas, en número de 20-30 por fruto.

\section{Origen: América del Sur.}

Importancia Económica: Es una especie tolerante a la sequí, sales y arenas. Se utiliza como especie ornamental y como cortina rompevientos. La madera es dura, usada para la construcción de puertas y pisos, para parquet, cascos de vino. El valor como forrajera es escaso o nulo porque es muy raramente consumida por el ganado doméstico.

\section{Leucaena leucocephala (Lam.) De Wit. "Vilquilla, aroma blanco"}

Árbol o arbusto, de crecimiento rápido, inerme.

Hojas compuestas bipinnadas, de $8-20 \mathrm{cms}$. de largo, peciólo con glándula, con cuatro a ocho pares de pinnas, las pinnas se forman de 1015 pares de folíolos semilanceolados, pequeñas de $5-15 \mathrm{~mm}$. de largo por $2 \mathrm{a}$ $4 \mathrm{~mm}$. de ancho.

Las flores reunidas en capitulos con cien a doscientas flores diminutas, en el ápice de las ramas, 1-3 por cada axila. Cáliz verdoso con 5 sépalos. Corola con 5 pétalos blancos. Androceo con estambres diplostémonos (10), libres. Gineceo con ovario súpero unicarpelar.

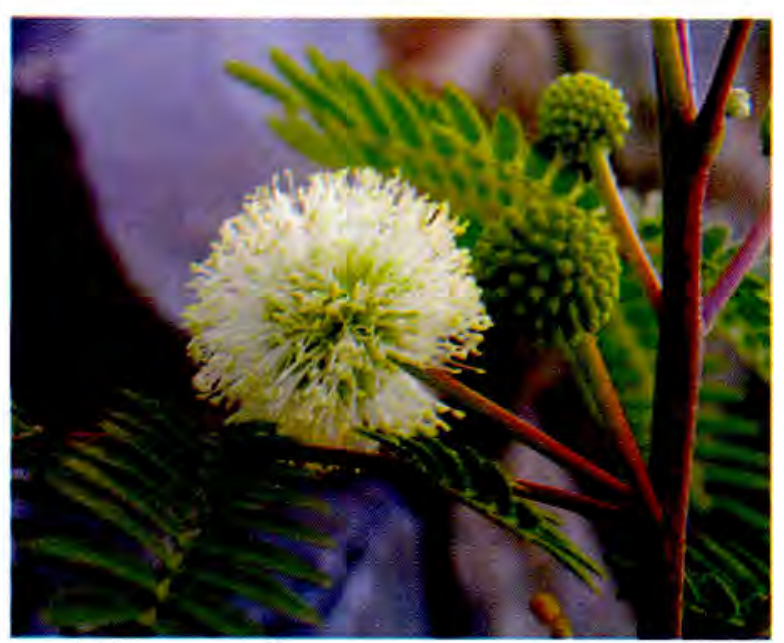

Figura $N^{\circ}$ 3: Leucaena leucocephala "Vilquilla" Se multiplica por semillas.

Los frutos son vainas alargadas, que nacen del receptáculo del capítulo, membranáceas, rectas, dehiscentes, de consistencia papirácea. Miden 10-15 cms. de largo.

Semillas planas, transversales, elípticas, miden 11-19 $\mathrm{mm}$. de largo por 15-21 mm. de ancho, de color marrón.

Origen: América Central.

Importancia Económica: Es una especie forrajera, cuando las vainas son tiernas. En la rehabilitación de terrenos agotados o como fuente de combustible.

\section{Prosopis pallida H.B.K. "Algarrobo"}

Árbol que puede llegar a medir hasta $20 \mathrm{~m}$. de altura en la costa norte del Perú, en nuestro departamento es escaso y mide mucho menos. El tronco es irregular, como una corteza externa de color pardo gris negruzca, fisurada. La copa extendida con ramas que muchas veces llegan al suelo.

Hojas compuestas, perennes, Peciolo corto. Pinnas elípticas, de margen entero.

Inflorescencia: Espiga axilar, las flores son hermafroditas, actinomorfas, pequeñas, de color amarillo pálido. Cáliz acampanado con cinco sépalos, la corola presenta pétalos libres. Androceo con estambres en número de 10 libres. Gineceo con ovario súpero unicarpelar.

Fruto: Vaina o legumbre, de $10-30 \mathrm{~cm}$. De longitud, 1$1.5 \mathrm{~cm}$. De ancho y de $5-9 \mathrm{~mm}$. de espesor, con pulpa dulce y carnosa.

Semillas: de forma ovoide y aplanada, de 20-30 por vaina o legumbre, color gris o pardo.

Origen: América del Sur.

Importancia Económica: Como alimento, sus frutos son llamados algarrobas, contienen azúcares, proteínas, minerales, vitaminas de complejo B y fibra. Con los frutos se prepara algarrobina que es un energizante natural.

Como forrajera: Las hojas las consumen el ganado ovino y caprino, los frutos también sirven de alimento para otro tipo de ganado.

En apicultura: por la abundancia de flores, son visitadas por las abejas que producirán miel, jalea, polen y cera.

En agroforesteria: Proporciona sombra al ganado, se utiliza como cortina rompevientos y para cerco vivo.

Su madera es empleada para construcción de viviendas rurales, mesas, vigas, puertas, bancas.

\section{Caesalpinia spinosa (Mol.) OK. "Tara"}

Árbol o arbusto más o menos aculeado, subglabro. Corteza de color marrón claro o gris oscuro. Ramas retorcidas. Hojas compuestas bipinnadas, con 6-8 pares 
de folíolos opuestos, lisos, glabros de color verde claro en haz y envés cuando jóvenes y verde oscuras cuando adultas. Las hojas miden de $8-12 \mathrm{~cm}$. de largo y los folíolos de 2.5-3.5. En el raquis hay espinas en pares por cada par de folíolos. También hay presencia de espinas en los peciolos.

Las flores reunidas en racimos multifloros, hermafroditas, cigomorfas. El sépalo inferior de borde muy dividido, fimbriado. Corola amarilla con 5 pétalos libres. Androceo con estambres del largo de los pétalos. Ovario súpero.

Vainas maduras de color rojizo amarillento. Tamaño de 8-10 cm. de largo. Indehiscentes, lineales y planas. Semillas ovoides, ligeramente aplastadas.

Se multiplica por semillas.

Origen: América del Sur (Perú)

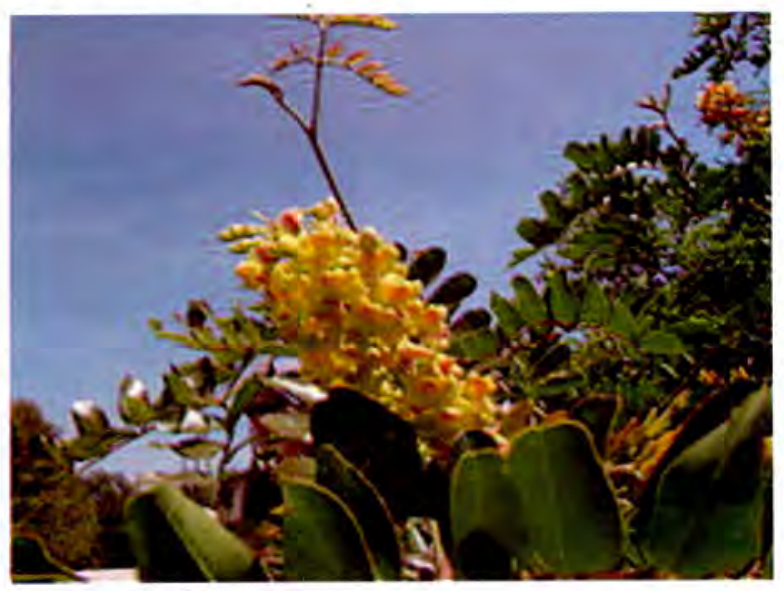

Figura $N^{\circ} 4$ : Caesalpinia spinosa "Tara"

Importancia Económica: Esta especie tiene muchos usos. Se emplea como especie ornamental por sus coloridas flores. Como fuente de taninos para el curtido de pieles. Tiñe de color negro, las raíces pueden teñir de color azul oscuro.

La goma de las semillas se usa para estabilizar y emulsionar alimentos. Sus frutos en infusión se usan para gargarismos contra la amigdalitis.

Se la utiliza también como cerco vivo.

Geoffroea decorticans (Hollk. \& Arn.) "Chañar o Chanal"

Árbol inerme o con espinas. Copa rígida, no péndula. Corteza gris exfoliante.

Hojas pinnadas, Folíolos subcoriáceos, caducos., son alternos y subopuestos, 3-13 por hoja, en general 5-9, enteros, glabros o finamente pubérulos de $5-15 \mathrm{~mm}$. de longitud, el folíolo terminal mayor que los laterales.

Flores pediceladas agrupadas en racimos simples axilares y apicales, aparecen antes que las hojas en primavera. La corola papilionácea, con pétalos de color amarillo.

Fruto una drupa subglobosa de mesocarpio carnoso y endocarpio leñoso, con 1-2 semillas de tegumento tenue, fusiformes y onduladas en la superficie.

Origen: Nativo de América del Sur.

Importancia Económica: Es un árbol con múltiples aplicaciones, no sólo desde el punto de vista ecológico sino porque es recomendable para cerco vivo, cortaviento natural, abrigo para el ganado. Forrajera por los frutos.

Especie cuya madera semidura blanco-amarillenta se emplea para enseres domésticos, para mangos de herramientas, muebles rústicos.

Los frutos se usan para preparar dulces.

Además es especie nectarifera, acudiendo a ella los picaflores.

\section{Eucalyptus camaldulensis Dehnh "Eucalipto"}

Árbol de gran porte, crece hasta $20 \mathrm{~ms}$. Su corteza (ritidomas) es gruesa, esponjosa, mezclando colores rojizos, grises, verdosos y blancuzcos. Ramas extendidas ramitas péndulas.

Hojas juveniles, opuestas pecioladas, las adultas lanceoladas, falcadas de $10-20 \mathrm{cms}$. de largo.

Las flores son pediceladas, reunidas en umbelas axilares, con más de 4 flores, sobre pedúnculos cilindricos. Pimpollos generalmente no mayores de 4 $\mathrm{mm}$. de diámetro, con el opérculo comúnmente rostrado no mayor de 5-6 mm. de largo. Anteras con las tecas paralelas, dehiscentes por hendiduras longitudinales.

Se multiplica por semillas.

Origen: Australia.

Importancia Económica: Resistente a la sequía, frío y con rápido crecimiento. Su madera brillante rojiza, oscila entre rosa suave a rojo negruzco, es muy quebradiza.

Se utiliza para mueblería fina por el color rojizo profundo.

Se le emplea también para leña. La madera produce excelente carbón. Es una especie polinizante con abejas.

Es una de las especies más sembradas mundialmente.

\section{Eucalyptus globulus Labill "Eucalipto"}

El Eucalyptus globulus Labill es un árbol de gran porte, con el tronco a menudo retorcido, liso o con la corteza lisa y caediza. Posee dimorfismo foliar. Sus hojas juveniles basales son glaucas, sésiles, opuestas, fuertemente aromáticas, dispuestas sobre ramitas 
cuadrangulares. Las adultas alternas falcadas. pecioladas de 10-20 cms. de largo. Las flores solitarias axilares, sésiles o subsésiles, de color blanco. Pimpollos florales rugosos, hasta de $20 \mathrm{~mm}$. de diámetro, cubiertos por una eflorescencia blanquecina. Opérculo anchamente cónico, rugoso, glauco más o menos de 2 cms. de diámetro. Estambres numerosos, pluriseriados, largamente exsertos. Ovario ínfero 3-6 lóculos pluriovulados, estilo filiforme.

Fruto cónico, truncado de $2-3 \mathrm{cms}$. de diámetro, rugoso, glauco, con el borde superior saliente, redondeado, y con las valvas poco notables. Semillas pequeñas. Se multiplica por semillas.

Origen: Australia, Tasmania.

Importancia Económica: Este árbol es forestal, ornamental y medicinal. De sus hojas, con fuerte olor a eucaliptol, se extraen aceites que al ser destilados se destinan a las industrias químico-farmacéuticos y de confiteria. En medicina popular se utilizan sus hojas en infusiones y vapores.

La madera tiene cualidades técnicas que la hacen muy requerida en la industria de la celulosa y como madera propiamente dicha. Se emplea también en la elaboración de papel fino. Su madera es utilizada en la producción de muebles para el hogar y oficinas y su chapa se destina al forrado de tableros.

\section{Schimus molle L. "Molle-Falso pimentero"}

Es un árbol frondoso siempre verde. Normalmente alcanza de 6-8 $\mathrm{m}$. pero llega a medir hasta $15 \mathrm{~m}$. de altura.

El tronco es robusto, ramificado, ramas colgantes. Corteza áspera de color pardo oscuro. Exuda una resina lechosa pegajosa, que en contacto con el aire toma un color blanco brillante.

Las hojas son compuestas imparipinnadas, de $10-30 \mathrm{~cm}$. de largo, con 7-25 pares de foliolos, de peciolo largo y aplanado. Los folíolos son alternos u opuestos, sésiles. lanceolados de 2.5 - a $6 \mathrm{~cm}$. de largo, de color verde ceniciento a color verde claro, poseen abundante resina aromática.

La inflorescencia es una panicula que pude llegar a medir desde los 8 a $30 \mathrm{~cm}$. Las flores son unisexuales, pequeñas abundantes, de color blanco anarillento, actinomorfas.

El cáliz en forma de copa con 5 sépalos. Androceo con 10 estambres dispuestos en dos series. Gineceo con el ovario súpero tricarpelar, con una cavidad fértil.

Fruto carnoso drupáceo, pequeño, seco en la madurez, globoso de color rojo-púrpura. Pulpa mucilaginosa y dulce. de sabor picante.

Semillas esféricas, de color marrón a negro. Una semilla por cada fruto. Se multiplica por semillas.

\section{Origen: Sudamérica (Perú).}

Importancia Económica: El molle es una especie ornamental y forestal. Los taninos de su corteza se emplean para curtiembre. Su madera es relativamente buena para leña y carbón, para mangos de herramientas. para pisos interiores. Con los frutos se elabora chicha.

Al frotar con hojas partes del cuerpo son buenos repelentes contra el ataque de insectos. También el humo los ahuyenta.

En algunos lugares el cocimiento de las hojas, ramas, corteza y raiz se emplea para teñir de color amarillo pálido, tejidos de lana y algodón. En otros, se le emplea como condimento, por su aroma y sabor picante, pero su uso es cada vez menor, ya que causa daño a la salud.

Los frutos son consumidos por aves. de ésta manera causan la dispersión de las semillas.

\section{CONCLUSIONES}

1. Se ha realizado el estudio morfotaxonómico de 16 especies arbóreas nativas y exóticas.

2. De las 16 especies estudiadas 01 pertenece a la División Pinophyta y 15 a la División Magnoliophyta.

3. Del total de especies, la familia con mayor representatividad es la familia Fabaceae $(07)$, y las familias Salicaceae y Myrtaceae con 2 especies cada una.

4. Se ha observado que varias de las especies estudiadas, tiene un potencial milifero para la apicultura, es el caso de los géneros Prosopis y Eucalyptus

Las especies forestales sirven como cerco vivo o cortina rompevientos.

\section{REFERENCIAS BIBLIOGRÁFICAS}

Brack Egg Antonio (2000) Ecología del Perú. Ed. Bruĩo. Lima-Perú.

Pretell Chiclote José (1985). Apuntes sobre algunas especies forestales nativas de la sierra peruana. Proyecto FAO/Holanda/INFOR. Lima-Perú.

Reynel R y León (1990). Árboles y arbustos andinos para agroforestería y conservación de suelos. Proyecto FAO/Holanda/DGRR, Lima-Perú.

Zegarra Zegarra, Rosario (2006) Biodiversidad ecosistemas y taxonomía de la vegetación desértica de Tacna. UNJBG. Tacna-Perú.

\section{Correspondencia:}

Rosario Elena Zegarra Zegarra

Ciudad Universitaria Fundo "Los Granados"

Calle Miraflores s/n. Tacna. Perú.

rosariozegarra13@hotmail.com 